\title{
Joseph D. Zuckerman (Vol. ed.), Joseph P. Iannotti, Anthony Miniaci, Gerald R. Williams, Joseph D. Zuckerman (eds): Disorders of the shoulder: diagnosis and management
}

\author{
3rd Edition, Wolters Kluwer, Lippincott Williams \& Wilkins, 2014, 328 pp, numerous \\ illustr., Hardcover, EUR 276,08 (Amazon), ISBN 13: 978-1-4511-3057-7
}

Pierre Kehr ${ }^{1}$

Received: 24 July 2015/Accepted: 25 July 2015/Published online: 4 September 2015

(C) Springer-Verlag France 2015

The traumatic and chronic lesions of all the articulations of the shoulder are treated in this work, very complete and very quite illustrated.

The first part relates to the proximal humeral fractures. Chapter 1 is devoted to classifications of the fractures of the humerus proximal; it is followed by the non-operative treatments. Then the various methods of osteosynthesis are exposed; one regrets in the bibliography of this chapter the absence of the references on the nail "Telegraph", developed in France by Dr. Christian Cuny. Chapter 4 is devoted to the prosthetic treatment of the fractures. Chronic dislocation and its treatments are treated in chapter 5. Finally an important chapter 6 is devoted to the complications of these fractures.

The second part exposes the fractures of the clavicle with there still classifications, the non-operative treatment, the techniques of osteosynthesis, the complications.

The fractures of the scapula are the object of the third part with there also classifications, the non-operative treatment, the techniques of osteosynthesis, the complications.

The acromio-clavicular injuries are the object of the fourth part, and the sterno-clavicular injuries are the fifth part with the same plan as the above-mentioned parts.

Finally a sixth part is devoted to the fractures of the shoulder at the adolescents with focus on epiphyseal lesions.

Each chapter is followed of a rich bibliographical reference, and the book ends in an index allowing to the reader in a direct access with the various entries.

Deliver intended for all the traumatologists specialized in the lesions of the various articulations of the shoulder, which they are already confirmed or initial.

Compliance with ethical standards

Conflict of interest None.

Pierre Kehr

pierre.kehr@gmail.com

1 Strasbourg, France 